\title{
Complementary Medicine Research
}

Founded 1994 as «Forschende Komplementärmedizin» by P. Jüni (Bern), D. Melchart (Munich), A. Stacher (Vienna), M. Ullmann (Munich)

\section{Editor-in-Chief}

Harald Walach - Poznan Medical University, Department of Pediatric Gastroenterology, Poznan, Poland

\section{Honorary Editor}

Reinhard Saller - University Clinic Zurich, Institute of Naturopathy, Department of Internal Medicine, Zurich, Switzerland

\section{Associate Editors}

Holger Cramer - KEM, ev. Kliniken Essen-Mitte, Knappschafts-Krankenhaus, Clinic for Naturopathy and Integrative Medicine, Essen, Germany

Tobias Esch - University Witten/Herdecke, Institute of Integrative Health Care and Health Promotion, Witten, Germany

Corina Güthlin - Johann Wolfgang Goethe University, Institute of General Medicine, Frankfurt/M., Germany

Stefanie Joos - University Clinic Tübingen, Institute of General Medicine and Interprofessional Care Tübingen, Germany

Jost Langhorst - Klinikum am Bruderwald, Sozialstiftung Bamberg, Clinic for Integrative Medicine and Naturopathy, Bamberg, Germany

David Martin - University Witten/Herdecke, Faculty of Health, Department of Human Medicine, Herdecke, Germany

Karin Meißner - Coburg University, Department of Social Work and Health, Coburg, Germany Dieter Melchart - Technical University Munich, Klinikum rechts der Isar, KoKoNat, Munich, Germany Jörg Melzer - University of Zurich, Zurich, Switzerland; Lou Andreas-Salomé Institute, Göttingen, Germany

Thomas Ostermann - University Witten/Herdecke, Department for Psychology and Psychotherapy, Witten, Germany

Matthias Rostock - Universitary Cancer Center Hamburg (UCCH), University Hospital Hamburg-Eppendorf, Hamburg, Germany

Michael Teut - Berlin, Germany

Michael Walkenhorst - Forschungsinstitut für biologischen Landbau (FiBL), Section Veterinary Health, Frick, Switzerland

\section{Editorial Board}

Dennis Anheyer - KEM, ev. Kliniken Essen-Mitte, Clinic for Naturopathy and Integrative Medicine, Essen, Germany

Jürgen Barth - University Clinic Zurich, Institute of Complementary and Integrative Medicine, Zurich, Switzerland

Stephan Baumgartner - University of Bern, KIKOM c/o Verein für Krebsforschung, Bern, Switzerland 


\section{Complementary Medicine Research}

(Continued)

Maya Bräm - Möhlin, Switzerland

Rainer Brenke - Berlin, Germany

Arndt Büssing - University of Witten/Herdecke, Chair of Medical Theory and Complementary Medicine, Herdecke, Germany

Maja Dal Cero - Schaffhausen, Switzerland

Gustav Dobos - Kliniken Essen Mitte, Internal Medicine V, Naturopathy and Integrative Medicine, Essen, Germany

Beatrix Falch - Phytocura, Zurich, Switzerland

Torkel Falkenberg - Karolinska Institutet, Department of Neurobiology, Care Sciences and Society, Huddinge, Sweden

Matthias Fink - Hannover Medical School, Clinic of Physical Medicine, Hannover, Germany

Lorenz Fischer - University of Bern, Inselspital, Institute of Complementary and Integrative Medicine, Bern, Switzerland

Vinjar Fønnebø - University of Tromsø, National Research Center on Complementary \& Alternative Medicine, Tromsø, Norway

Michael Frass - University Clinic for Internal Medicine I, Vienna, Austria

Josef Hummelsberger - International Society for Chinese Medicine SMS, Munich, Germany

Dominik Irnich - University Clinic of the LMU Munich, Pain Ambulance - Clinic for Anesthesiology, Munich, Germany

Detmar Jobst - University Hospital of Bonn, Institute of General Practitioners, Bonn, Germany Christan Kessler - Immanuel Krankenhaus Berlin, Department for Naturopathy, Berlin, Germany

Anna K. Koch - KEM, ev. Kliniken Essen-Mitte, Center for Integrative Gastroenterology, Essen, Germany

Niko Kohls - Lenggries, Germany

Matthias Kröz - Gemeinschaftskrankenhaus Havelhöhe, Clinic for Internal Medicine, Berlin, Germany

Wolfgang Kubelka - University of Vienna, Pharma Center, Institute of Pharmacognosy, Vienna, Austria

Kenny Kuchta - Research Center for Far Eastern Medicine, Göttingen, Germany

Romy Lauche - Klinikum im Bruderwald, Department of Internal and Integrative Medicine, Bamberg, Germany

Klaus Linde - Technical University Munich, Klinikum rechts der Isar, Institute for General Medicine, Munich, Germany

Rainer Lüdtke - DSZ - Deutsches Stiftungszentrum GmbH, Essen, Germany

Hugh MacPherson - York, UK

Harald Matthes - Gemeinschaftskrankenhaus Havelhöhe, Medical Clinic Focus Gastroenterology, Berlin, Germany

Beat Meier - ZHAW - Zürcher Hochschule für angewandte Wissenschaften, Section Phytopharmacy, Zurich, Switzerland

Susanne Moebus - University Clinic Essen, Institute of Medical Informatics, Essen, Germany

Albrecht Molsberger - Düsseldorf, Germany

Menachem Oberbaum - Shaare Zedek Medical Center, Jerusalem, Israel

Miriam Ortiz - Charité, University Medicine Berlin, Institute for Social Medicine, Epidemiology and Health Economics, Berlin, Germany

Florian Pfab - Munich, Germany

Karl-Ludwig Resch - German Institute for Health Research, Bad Elster, Germany

Paolo Roberti di Sarsina - Fondazione per la Salutogenesi ONLUS, Bologna, Italy

Gabriele Rotter - Charité, University Medicine Berlin, University Outpatient Clinic for Complementary Medicine, Berlin, Germany

Yvonne Samstag - University Clinic Heidelberg, Institute for Immunology, Section Molecular Immunology, Heidelberg, Germany

Marc Schlaeppi - St. Gallen Cantonal Hospital, Center for Integrative Medicine, St. Gallen, Switzerland 


\section{Complementary Medicine Research}

(Continued)

Stefan Schmidt - University Clinic Freiburg, Department of Psychosomatic Medicine and Psychotherapy, Freiburg i.Br., Germany

Harmut Schröder - Europe University Viadrina, Institute of Transcultural Health Sciences, Frankfurt/O., Germany

Herbert Schwabl - Padma AG, Wetzikon, Switzerland

Florian Schwerla - Munich, Germany

Rainer Stange - Charité, University Medicine Berlin, Department of Naturopathy, Berlin, Germany

Diana Steinmann - Hannover, Germany

Trine Stub - The Arctic University of Norway (NAFKAM), Department of Community Medicine,

Faculty of Health Science, Troms $\varnothing$, Norway

Karin Stockert - Sigmund Freud University, Department for Complementary Medicine,

Vienna, Austria

Wolfram Stör - Icking, Germany

Christian Terreaux - Vifor AG, Villars-sur-Glâne, Switzerland

Bernhard Uehleke - Berlin, Germany

Gudrun Ulrich-Merzenich - Medical University Policlinic Bonn, Bonn, Germany

Jan Valentini - Tübingen University Hospital, Institute for General Practice and Interprofessional Care, Tübingen, Germany

Sabine Vollstedt - Bokholt-Hanredder, Germany

Caroline S. Weckerle - University of Zurich, Institute of Systemic Botany, Zurich, Switzerland Axel Wiebrecht - Berlin, Germany

Françoise Wilhelmi de Toledo - Klinik Buchinger am See, Clinic for Therapeutic Fasting and Integrative Medicine, Überlingen, Germany

Stefan N. Willich - Charité, University Medicine Berlin, Institute of Social Medicine, Berlin, Germany Ursula Wolf - University of Bern, Institute of Complementary Medicine, Bern, Switzerland 
S. Karger

Medical and Scientific Publishers

Basel $\cdot$ Freiburg $\cdot$ Hartford $\cdot$ Oxford •

Bangkok • Dubai $\cdot$ Kuala Lumpur

Melbourne $\cdot$ Mexico City $\cdot$ Moscow $•$

New Delhi $\bullet$ Paris $\cdot$ Shanghai $\cdot$ Tokyo
Disclaimer

The statements, opinions and data contained in this publication are solely those of the individual authors and contributors and not of the publisher and the editor(s). The appearance of advertisements in the journal is not a warranty, endorsement, advertisements in the journal is not a warranty, endorsement,
or approval of the products or services advertised or of their or approval of the products or services advertised or of their
effectiveness, quality or safety. The publisher and the editor(s) disclaim responsibility for any injury to persons or property resulting from any ideas, methods, instructions or products referred to in the content or advertisements.

Drug Dosage

The authors and the publisher have exerted every effort to ensure that drug selection and dosage set forth in this text are in accord with current recommendations and practice at the time of publication. However, in view of ongoing research, changes in government regulations, and the constant flow of information relating to drug therapy and drug reactions, the reader is urged to check the package insert for each drug for any change in indications and dosage and for added warnings and precauin indications and dosage and for added warnings and precau-
tions. This is particularly important when the recommended agent is a new and/or infrequently employed drug.
All rights reserved.

No part of this publication may be translated into other languages, reproduced or utilized in any form or by any means, electronic or mechanical, including photocopying, recording microcopying, or by any information storage and retrieva system, without permission in writing from the publisher or in the case of photocopying, direct payment of a specified fee to the Copyright Clearance Center (see "General Information").

(c) Copyright $2019 / 2020$ by S. Karger AG,

CH-4009 Basel (Switzerland)

Printed on acid-free and non-aging paper (ISO 9706) 
No. 1

1 Publisher's Note

Editorial

3 A Joint Statement for "Tighter Regulation" of Traditional Chinese Medicine Issued by the Federation of European Academies of Medicine (FEAM) and the European Academies' Science Advisory Council (EASAC): Scare Stories or Obstruction of Access?

Melchart, D. (Munich)

Research Articles / Originalarbeiten

6 Entelechy Regained? Further Musings on a Quantised Gyroscopic Metaphor for the Vital Force in Health and Dis-Ease

Milgrom, L.R. (London)

19 Is Mindfulness-Based Stress Reduction a Promising and Feasible Intervention for Patients Suffering from Migraine? A Randomized Controlled Pilot Trial

Simshäuser, K.; Lüking, M. (Freiburg); Kaube, H. (Freiburg/Munich);

Schultz, C. (Freiburg/Gundelfingen); Schmidt, S. (Freiburg)

31 Long-Term Survival Outcomes of Metabolically Supported Chemotherapy with Gemcitabine-Based or FOLFIRINOX Regimen Combined with Ketogenic Diet, Hyperthermia, and Hyperbaric Oxygen Therapy in Metastatic Pancreatic Cancer Iyikesici, M.S. (Bahcelievler/Istanbul)

40 The Effect of Cynara scolymus on Blood Pressure and BMI in Hypertensive Patients: A Randomized, Double-Blind, Placebo-Controlled, Clinical Trial

Ardalani, H. (Tehran/Copenhagen); Jandaghi, P. (Qazvin); Meraji, A. (Kermanshah); Hassanpour Moghadam, M. (Mashhad)

Systematic Review / Systematische Übersichtsarbeit

47 Xiaoyaosan Produces Antidepressant Effects in Rats via the JNK Signaling Pathway

Zhao, H.-B.; Jiang, Y.-M.; Hou, Y.-J.; Yan, Z.-Y.; Liu, Y.-Y. (Beijing); Li, X.-J. (Guangzhou); Gong, W.-J. (Beijing)

Case Report / Kasuistik

55 The Potential to Source a Patient's Imaginative Powers in Treating Cancer: Illustrated in Three Cases Roesch, M. (Bochum)

61 PharmaNews

62 Book Review

63 Society Bulletins
No. 2

Editoria

67 Neue Definitionen der Integrativen Medizin: Alter Wein in neuen Schläuchen?

Esch, T. (Witten); Brinkhaus, B. (Berlin)

75 Journal Club

Research Articles / Originalarbeiten

77 A Proposal for a System of Classification for Anthroposophic Meditation

Sparby, T. (Witten)

89 Completion Rates and Clinical Changes of Patients Seeking Non-Invasive Treatment for Low Back Pain in 13 Centres of a Sports Medicine Institute in India Rajamani, P. (Chennai); Shewade, H.D. (New Delhi/Paris); Kundu, D. (New Delhi); Sekaran, K.K.; Amalan, S.D.; Pugazhendi, S.; Pugazhendi, K. (Chennai)

97 The Effect of Individualized Developmental Care Practices in Preterm Infants

Küçük Alemdar, D. (Giresun); İnal, S. (Istanbul)

Review Article / Übersichtsarbeit

105 KOKON: A Germany-Wide Collaborative Research Project to Identify Needs, Provide Information, Foster Communication and Support Decision-Making about Complementary and Alternative Medicine in Oncology Güthlin, C. (Frankfurt); Bartsch, H.-H. (Freiburg); Joos, S. (Tübingen); Längler, A. (Witten-Herdecke); Lampert, C. (Hamburg); Ritter, C. (Greifswald); Schildmann, J. (Halle-Wittenberg); Weis, J. (Freiburg); Wilhelm, M. (Nürnberg); Witt, C.M. (Berlin); Horneber, M. (Nürnberg)

Brief Report / Forschungsbericht

112 Echinacea for Cancer Patients: To Give or Not to Give Tafazoli, A. (Tehran)

Commentary / Kommentar

117 Das Gegenteil von Evidence-Based Journalism: Der MedWatch-Artikel zum "vermeintlichen Mistel-Wunder"

Kiene, H. (Freiburg) 
Abstract Service

123 Artikel, die Sie nicht versäumen sollten

126 Society Bulletins / Gesellschaftsmitteilungen

No. 3

Editorials

129 Replizierbarkeit - das ewige Totschlagargument gegen die Homöopathie und andere unliebsame Dinge Walach, H. (Poznan)

131 Quantified Complementary and Alternative Medicine: Convergence of Digital Health Technologies and Complementary and Alternative Medicine Steckhan, N. (Berlin/Potsdam); Arnrich, B. (Potsdam)

\section{Journal Club}

Research Articles / Originalarbeiten

143 Antifungal in vitro Activity of Essential Oils against Clinical Isolates of Malassezia pachydermatis from Canine Ears: A Report from a Practice Laboratory Bismarck, D. (Bad Kissingen); Dusold, A. (Bad Kissingen/ Coburg); Heusinger, A.; Müller, E. (Bad Kissingen)

155 Cardiovascular Responses and Cardiac Work of Selected Daily Activities in Young Healthy Indian Participants

Fredrick, J. (Puducherry); Vaz, M. (Bengaluru)

163 The Multicomponent, Multitarget Therapy SUC in Cats with Chronic Kidney Disease: A Multicenter, Prospective, Observational, Nonrandomized Cohort Study

Brandenburg, U. (Göttingen); Braun, G. (Munich); Klein, P. (Rohrbach); Reinhart, E. (Baden-Baden)

Review Articles / Übersichtsarbeiten

174 Marsh Mallow (Althaea officinalis L.) and Its Potency in the Treatment of Cough

Mahboubi, M. (Kashan)

184 Apitherapy for Osteoarthritis: Perspectives from Basic Research

Jagua-Gualdrón, A.; Peña-Latorre, J.A. (Bogotá);

Fernadez-Bernal, R.E. (Bogotá/Cochabamba)

Case Report / Kasuistik

193 Individualized Homeopathic Treatment in Women with Recurrent Cystitis: A Retrospective Case Series Gaertner, K. (Witten); von Ammon, K.; Frei-Erb, M. (Bern)

201 Society Bulletins / Gesellschaftsmitteilungen
Editorials

207 The SARS-CoV-2 Crisis: Has Medicine Finally Entered a Reductionist Era?

Klement, R.J. (Schweinfurt)

209 Rationales, Irrationales, Komplexes in Zeiten einer Pandemie: One World

Melzer, J. (Zürich/Göttingen); Stahnisch, F.W. (Calgary)

215 Journal Club

Research Articles / Originalarbeiten

222 Educational Program in Complementary and Alternative Medicine for Cancer Self-Help Groups Jablotschkin, M.; Bartsch, H.H. (Freiburg i.Br.); Gschwendtner, K. (Heidelberg); wHauer, J. (Freiburg i.Br.); Horneber, M. (Nuremberg); Weis, J. (Freiburg i.Br.)

230 The Impact of Traditional Medicine-Based Lifestyle and Diet on Infertility Treatment in Women Undergoing Assisted Reproduction: A Randomized Controlled Trial Alibeigi, Z.; Jafari-Dehkordi, E. (Tehran); Kheiri, S.; Nemati, M. (Shahrekord); Mohammadi-Farsani, G.; Tansaz, M. (Tehran)

242 Dry Fasting Physiology: Responses to Hypovolemia and Hypertonicity

Papagiannopoulos-Vatopaidinos, I.-E.; Papagiannopoulou, M. (Berlin); Sideris, V. (Athens)

252 The Effect of Acupressure on the Severity of Nausea, Vomiting, and Retching in Pregnant Women: A Randomized Controlled Trial

Tara, F.; Bahrami-Taghanaki, H.; Amini Ghalandarabad, M.; Zand-Kargar, Z.; Azizi, H.; Esmaily, H.; Azizi, H. (Mashhad)

Systematic Review / Systematische Übersichtsarbeit

260 A Systematic Review and Meta-Analysis on the Survival of Cancer Patients Treated with a Fermented Viscum album L. Extract (Iscador): An Update of Findings Ostermann, T.; Appelbaum, S. (Witten); Poier, D. (Herdecke); Boehm, K. (Witten); Raak, C.; Büssing, A. (Herdecke)

272 Curcumin Preparations Can Improve Flow-Mediated Dilation and Endothelial Function: A Meta-Analysis Changal, K.H.; Khan, M.S. (Toledo, OH); Bashir, R. (Meerut); Sheikh, M.A. (Toledo, OH)

282 Expression of Concern

Letter / Brief an die Herausgeber

284 EsSalud, WHO Collaborating Center for Traditional and Complementary Medicine in Peru Vallejos-Gamboa, J.; HuacchoRojas, J.J.; VillarLopez, M. (Lima) 
Abstract Service

286 Latest Publications You Should Not Miss

291 Society Bulletins / Gesellschaftsmitteilungen

No. 5

Editorial

293 “... Every End Is a Beginning, Every Beginning Is an End ...": Thank You and Good-Bye to Karin Kraft, Frauke Musial, and Benno Brinkhaus

Walach, H. (BerlinPoznanWitten)

295 Journal Club

Research Articles / Originalarbeiten

302 Vitamin D3 Supplementation in Diarrhea-Predominant Irritable Bowel Syndrome Patients: The Effects on Symptoms Improvement, Serum CorticotropinReleasing Hormone, and Interleukin-6 - A Randomized Clinical Trial

Khalighi Sikaroudi, M.; Mokhtare, M.; Janani, L.;

Faghihi Kashani, A.H.; Masoodi, M.; Agah, S.; Abbaspour, N.; Dehnad, A.; Shidfar, F. (Tehran)

310 The Efficacy of Topical Basil Essential Oil on Relieving Migraine Headaches: A Randomized Triple-Blind Study

Ahmadifard, M.; Yarahmadi, S. (Khorramabad); Ardalan, A. (Burbank, CA); Ebrahimzadeh, F.; Bahrami, P.; Sheikhi, E. (Khorramabad)

319 Effect of Unilateral Left Nostril Breathing (Chandra Anga Pranayama) on Cognitive Function in Healthy Yoga-Naïve Individuals: A Randomized, Controlled, Pilot Study

Santhanam Kumar, S.S.; Kamath, A. (Manipal); Poojary, S. (Mangalore)

328 The Effect of Lavender Oil on Sleep Quality and Vital Signs in Palliative Care: A Randomized Clinical Trial Yıldırım, D.; Kocatepe, V.; Can, G.; Sulu, E.; Akış, H.; Şahin, G.; Aktay, E. (Istanbul)

336 Mapping Physicians' Experiences with Medicinal Products from Whole Medical Systems: A Descriptive Analysis of the Vademecum of Anthroposophic Medicines

Hamre, H.J.; Glockmann, A. (Freiburg); Marti, J. (Munich); Soldner, G. (Freiburg/Munich)

Systematic Review / Systematische Übersichtsarbeit

348 Effect of Cashew Nut on Lipid Profile: A Systematic Review and Meta-Analysis

Morvaridzadeh, M. (Kermanshah); Sepidarkish, M. (Babol); Farsi, F.; Akbari, A. (Tehran); Mostafai, R.; Omidi, A.

(Kermanshah); Potter, E. (Dallas, TX); Heshmati, J.

(Kermanshah)
Review Article / Übersichtsarbeit

357 Does the Spleen Have a Function in Digestion? Medical History, Phylogenetic and Embryological Development of the Splenogastric System Weinzirl, J.; Scheffers, T.; Garnitschnig, L.; Andrae, L.; Heusser, P. (Herdecke)

Case Report / Kasuistik

364 A Case Report of Acupuncture at Neiguan Point (P6) for Paroxysmal Supraventricular Tachycardia

Liu, P.; Li, C. (Guangzhou and Zhuhai); Lu, Y. (Guangzhou); Liu, Q. (Guangzhou and Zhuhai)

Retraction Statement

370 Society Bulletins / Gesellschaftsmitteilungen

No. 6

Editorial

375 100-Year Anniversary of Anthroposophic Medicine as an Integrative Medical System

Martin, D. (Herdecke/Tübingen)

379 Journal Club

Research Articles / Originalarbeiten

383 How Young German General Practitioners View and Use Complementary and Alternative Medicine: A Qualitative Study

Huber, C.M.; Barth, N.; Linde, K. (Munich)

392 Communication about Complementary and Alternative Medicine in Danish Oncological Settings: An Intervention Study

Nissen, N. (Nyborg); Laursen, S.S. (Odense); Rossau, H.K. (Nyborg)

401 The Protective Effect of Pre-Moxibustion on Reproductive Hormones Profile of Rats with Tripterygium Glycosides-Induced Ovarian Damage Zhu, S.; Wang, Y.; Chang, X.; Chen, H.; Jin, X. (Nanjing)

410 Synergistic Antimicrobial and Antioxidant Properties of Coccinia grandis (L.) Voigt, Clerodendrum inerme (L.) Gaertn. and Acanthus ebracteatus Vahl. Extracts and Their Potential as a Treatment for Xerosis Cutis Pratoomsoot, C. (Phitsanulok/Nottingham); Wongkattiya, N. (Chiang Mai); Sanguansermsri, D. (Phitsanulok)

421 The Effect of Aromatherapy on Sleep and Quality of Life in Menopausal Women with Sleeping Problems: A Non-Randomized, Placebo-Controlled Trial Gürler, M. (Kırşehir); Kızılırmak, A. (Nevşehir); Baser, M. (Kayseri) 
431 Analysis of Oncological Second Opinions in a Certified University Breast and Gynecological Cancer Center in Relation to Complementary and Alternative Medicine Hack, C.C.; Wasner, S.; Meyer, J.; Häberle, L.; Jud, S.; Hein, A.; Wunderle, M.; Emons, J.; Gass, P.; Fasching, P.A.; Egloffstein, S.; Beckmann, M.W. (Erlangen); Lux, M.P. (Erlangen/Paderborn); Loehberg, C.R. (Erlangen)

440 Effectiveness of Aromatherapy for Relief of Pain, Nausea, and Vomiting after Percutaneous Nephrolithotomy: A Randomized Controlled Trial Amirhosseini, M.; Dehghan, M.; Mangolian Shahrbabaki, P.; Pakmanesh, H. (Kerman)
Brief Report / Forschungsbericht

449 Traditional Chinese Eight Brocade Exercise Prescription for Ankylosing Spondylitis: A Quantitative Synthesis

Zou, Y.-Y.; Zhang, H.-Y.; Xue, L.; Ye, J.-J. (Nanjing); Hu, G.-Y. (Jiangyin)

454 Acknowledgement to Reviewers

456 Society Bulletins 